\title{
The Combination and Development of Chemistry and Chemical Engineering and Computer Technology
}

\author{
Yunshen Zhang \\ Department of Petrochemical Engineering, Puyang Vocational and Technical College, \\ puyang457000, China.
}

Keywords: Chemical engineering, computer technology, combines.

\begin{abstract}
20th century, the development of the computer industry affected all aspects of life, and also promoted the social transformation and development in various industries, led human into the new civilized era that information and knowledge exploded, computer technology and information technology were also widely used in the development of various disciplines and various industries. As one of the pillar industries of economic development, the chemical industry got a rapid development because of the development on the combination of computer technology, at present, computer chemistry has become the most important research. This paper focused on the combination of chemistry and computer technology, first introduced the combination of chemistry and computer technology, mainly described the application of computer technology in chemical engineering design, chemical production, and chemical engineering education and so on according to the current background, as well as the application of chemical disciplines in information retrieval, chemical analysis, artificial intelligence and other issues on the specific development, finally, put forward the prospect of computer chemistry.
\end{abstract}

\section{The COMBINATION OF CHEMICAL ENGINEERING AND COMPUTER TECHNOLOGY}

\subsection{Overseas Development Course}

The development of chemical knowledge innovation promoted the rise of computer chemistry. The object of chemistry research is complex, the research object of chemistry is mainly compound whose variety is numerous and complex. Chemical is a complex subject which has a variety of disciplines integration, the research and analysis is very difficult. The advantage of computer technology lies in its powerful computing ability, storage capacity and logical judgment when processing information. If we can make the chemistry and computer technology a combination, we can improve research efficiency, save a lot of manpower and resources and other related resources to accelerate the pace of development of disciplines, thus began a combination of computer and chemical chemistry. To the 1980s, the computer technology began to be widely used in various branches of chemical disciplines; since the 21 st century, the rapid advances in computer technology promoted the rapid development of chemical 
and chemical disciplines.

\subsection{Domestic Development Course}

1960s, compared to the prosperity and development of computer technology abroad, the domestic computer development is still a depression, software and hardware are developed with a large gap with foreign countries, as some people recognized the broad prospects for the development of computer technology, they has been focused on the integration of development issues of computer technology and chemical disciplines, in 1970, Chen Guanrong and Lu Huanzhang, two chief engineer of Chemical Engineering Design Institute, also advocated the use of computers to do chemical design, Lu Huanzhang even try to compile machine code program himself to do chemical calculations. When the national 12-year planning day, every industry put forward the idea of combining computer technology industry; finally in 1975, some domestic chemical design institute carried out the computer simulation software as the theme of the federation war, officially opened the prelude to the combination of computer technology and chemical applications, laid a foundation for the development of computer chemistry, subsequently, China released the engineering chemistry system simulation software developed by Professor Han Fanghuang on this basis.

\section{THE COMBINATION OF CHEMICAL ENGINEERING AND COMPUTER TECHNOLOGY}

Now with the help of computer technology, companies can simplify research procedures, shorten product development cycle, enterprise integrated competitiveness will also be enhanced with the improvement of the production efficiency. So people are increasingly recognized the value of computer applications in various industries. At present, the application of computer technology in chemical engineering is mainly concentrated in the fields of design, production, science and education.

simulate chemical design using computer and auxiliary drawing are two aspects of computer application and chemical design. Chemical design based on a large number of complex engineering calculations, accurate and rapid computer calculation and fine drawing can make freed from the cumbersome manual work.

Computer is also popular in scientific research and teaching activities as a powerful tool. When carrying out scientific research activities, you can use the computer to process complex data and calculate the complex values, for teaching activities, demonstration and performance effects are also more excellent using computer technology in the chemistry course.

\section{CHEMISTRY AND COMPUTER TECHNOLOGY}

Chemistry has the complexity that other disciplines can't compared, but the computer has a highly developed computing analysis and storage capacity, the perfect combination of these two brings surprising results for people. This paper introduces the application of computer technology in chemistry from four aspects: calculation of chemical information retrieval, computerization of 
chemical structure expression, application of computer in analytical chemistry, and application of artificial intelligence in chemistry.

The most direct means of describing a compound is the structural formula of the molecule, chemical structure is the basis of chemical research. But because of its graphical form is difficult to record, no matter what form of record, the chemical structure is difficult to deal with. In the development of computer hardware and graphics processing software, people succeeded in creating a chemical structure based on graph theory, which has been widely used in the description of the chemical structure, formed a database systems with storage, display and login, search and a series of other processing tools, successfully solved the computer representation and retrieval problems for chemical structure.

\section{SUGGESTIONS ON THE DEVELOPMENT OF COMPUTER CHEMISTRY IN CHINA}

With the development of China's economy and science and technology, the enhancement of comprehensive national strength, China has trained a number of outstanding research team and made a very good result, makes a great contribution to the development of computer chemistry. But China did not implement the commercialization of scientific research, enhance the effective supply of chemical science and technology achievements, and reverse the unfavorable situation that science and technology are out of touch with the economy.

In today's society, we shouldn't overlooked the ecological problems, green and sustainable development have made a request on the chemical product design, production and life cycle. What we need to do is to expand the scope of the study of chemistry, combine computer chemistry and ecological environmental protection, fully taking environmental issues into account in the process of design and production, to promote better and faster progress in chemistry and to create a better life for mankind.

\section{SUMMARY}

The combination of computer technology and chemical engineering gave birth to computer chemistry, computer technology has affected many fields of chemistry and chemical engineering, promoted the chemical disciplines into the rapid development era. Computer technology is widely used in chemical science, covering all areas of chemical industry, what is mentioned above is not perfect. It's not easy for China's computer chemistry research and development course to get today's results, but as a pillar industry of the national economy, research and analysis on chemical industry must not be stalled, we should continue to summarize the existing problems in the study and explore effective solutions to ensure rapid development.

\section{REFERENCES}

[1] Li Juchao, Common Computer Software in Chemistry, J. Chemical Engineering and Equipment. 03 (2008) 121-123. 
[2] Li Jinghai, Chemical Engineering in the 21st Century, J. Journal of Chemical Industry. 08 (2008) 1879-1883.

[3] Xu Zhihong, The Combination and Development of Chemistry and Chemical Engineering and Computer Technology, J. Computer and Applied Chemistry. 09 (2008) 1053-1056.

[4] Dao Jun, Discussion on the Combination of Chemistry and Chemical Engineering with Computer Technology, J. Chemical Management. 09 (2016) 85.

[5] Guo Yanting, Huang Xue, Chen Man, Feng Guangzhu, Progress in the Application of Computer in Chemical Engineering, J. Guangzhou Chemical Industry. 12 (2016) 28-30.

[6] Han Zheng, The Application of Computer in Chemical Engineering, J. Chemical Engineering and Equipment. 09 (2012) 154-156.

[7] Yang Qin, Pu Weiguang, Sui Zhijun, Wei Yongming, Application and Development of Computer in Chemical Engineering, J. Chemical World. 11 (2009) 697-699.

[8] Yuan Shengang, The Vanguard of Chemical Knowledge Innovation - Computer Chemistry, J. World Science and Technology Research and Development. 06 (1998) 117-120.

[9] Zhou Xiayu, Fu Hui, Liu Manzhen, The Development, Application and Prospect of Computer Chemistry, J. China Science and Education Innovation Guide. 14 (2012) 12. 